\title{
Rancang Bangun Plastic Waste Shredder untuk Mengolah Sisa Limbah Plastik Proses Injection Mould
}

\author{
Arka Dwinanda Soewono $^{1 *}$, Jeremy Liutomo ${ }^{1,2}$, Marten Darmawan ${ }^{1}$ \\ ${ }^{1}$ Departemen Teknik Mesin, Universitas Katolik Indonesia Atma Jaya \\ Jalan Raya Cisauk, Bumi Serpong Damai, Tangerang Selatan, Banten 15345 \\ ${ }^{2}$ Mechanical and Automation Workshop, PT. Merdeka Milik Bangsa \\ Jalan Gatot Subroto No.34, Jakarta 12950 \\ *E-mail: arka.soewono@atmajaya.ac.id
}

Diterima: 16-10-2020; Direvisi: 29-03-2021; Dipublikasi: 27-04-2021

\begin{abstract}
Abstrak
Penggunaan material plastik sebagai bahan baku pilihan dalam perancangan komponen alat-alat elektronik semakin meningkat dikarenakan sifatnya yang mudah dibentuk, daya tahan yang tinggi dan harga yang terjangkau. Proses pengolahan plastik untuk selubung alat elektronik pada umumnya melibatkan proses cetak injeksi yang pada akhirnya menghasilkan limbah plastik dari cetakan yang cacat (Short Shot Mould) dan material sisa dari runner. Untuk mengurangi dampak negatif terhadap lingkungan, limbah plastik ini perlu didaur ulang. Oleh karena itu, dibuatlah mesin Plastic Waste Shredder yang bertujuan untuk mencacah limbah plastik sisa proses cetak injeksi sehingga dapat diolah kembali untuk menjadi produk yang baru. Pada makalah ini, proses perancangan dan pembuatan mesin pencacah menggunakan metode Pahl dan Beitz dengan bantuan software Solidworks. Proses perhitungan dan pemilihan komponen dibahas secara lengkap terutama untuk bagian alat pemotong, poros, sabuk transmisi dan rangka. Mesin pencacah ini dirancang untuk memiliki kapasitas input maksimum sebesar 2 liter/menit dan dapat menghancurkan plastik dengan dimensi panjang dan lebar sebesar $100 \mathrm{~mm}$ x $100 \mathrm{~mm}$ dengan ketebalan maksimum $2 \mathrm{~mm}$. Berdasarkan hasil uji coba, mesin tersebut dapat mencacah dan menghancurkan plastik dengan baik. Dari hasil pengukuran, mesin Plastic Waste Shredder memiliki kapasitas ouput rata-rata sebesar 1,84 liter/menit dengan shredding efficiency sebesar $95 \%$.
\end{abstract}

Kata kunci: daur ulang; limbah plastik; mesin pencacah; mesin penghancur

\begin{abstract}
The use of plastics as material of choice for designing electronic parts has become popular due to its moldability, high durability, and cost effectiveness. In general, injection moulding is employed in order to manufacture plastic casing for electronic equipments which in turn, generates plastic wastes in the form of defective mould (Short Shot Mould) and discarded runner. To minimiza their adverse impact on environment, these plastic wastes have to be recycled. Therefore, Plastic Waste Shredder was designed and built with the purposes of shredding unused plastics from injection moulding process so that they can be reused to create new products. In this paper, the design and construction process follow Pahl and Beitz method with assistance from Solidworks software. The strength calculations and component selections are discussed in detail, particularly for the shredder, drive shaft, transmission element and base frame. This plastic shredder is designed to habe a maximum input shredding capacity of 2 litre per minute and can be used to cut plastics up to $2 \mathrm{~mm}$ thick with a dimension of $100 \mathrm{~mm} \times 100 \mathrm{~mm}$. The results from experimental testing shows that the plastic shredder can cut the plastic wastes into small flakes as intended. Based on the experimental measurements, the Plastic Waste Shredder manages to produce average outpur capacity of 1.84 litre per minute with $95 \%$ shredding efficiency.
\end{abstract}

Keywords: crusher; plastic waste; recycling; shredder

\section{Pendahuluan}

Plastik banyak digunakan oleh industri maufaktur elektronik sebagai bahan baku utama untuk pembuatan selubung penutup (casing) perangkat elektronik karena plastik memiliki sifat yang flexibel, kuat, ringan, harganya yang sangat terjangkau dan tersedia dalam jumlah yang banyak. Proses pengolahan plastik untuk menjadi casing alat elektronik pada umumnya melibatkan proses cetak injeksi (injection moulding) yang dapat memproduksi produk dengan bentuk yang komplek secara massal dan cepat. Akan tetapi, salah satu produk sampingan dari cetak injeksi plastik (plastic injection 
Arka Dwinanda Soewono dkk /Jurnal Rekayasa Mesin p-ISSN: 1411-6863, e-ISSN: 2540-7678 Vol.16|No.1|1-8|April|2021

moulding) adalah adanya limbah plastik sisa dari runner yang dipakai pada saat proses pengisian cetakan [1,2]. Selain itu, sering juga terdapat cacat pada produk yang dihasilkan oleh proses cetak injeksi seperti porositas dan Short Shot Mould yang ikut berkontribusi meningkatkan jumlah limbah plastik [3,4]. Mempertimbangkan bahwa Indonesia merupakan salah satu peyumbang sampah plastik terbesar di dunia [5], proses daur ulang untuk limbah plastik dari hasil sampingan proses cetak injeksi di industri perlu dilaksanakan. Lebih jauh lagi, limbah plastik yang dihasilkan dari proses cetak injeksi biasanya memiliki tingkat kemurnian lebih baik dari 97\% sehingga tidak diperlukan proses penyortiran yang rumit pada saat proses daur ulang [6].

Proses daur ulang limbah plastik pada umumnya melibatkan penggunaan mesin pencacah plastik untuk mengurangi ukuran dan volume material sehingga dapat diproses lebih lanjut. Saat ini, berbagai tipe mesin pencacah plastik komersial telah ditawarkan di pasaran. Demikian juga, telah banyak penelitian dilakukan terkait penentuan desain dari mesin pencacah plastik [7 - 9]. Akan tetapi, desain dari mesin pencacah plastik yang ada lebih dioptimalkan untuk pengolahan botol plastik bekas sehingga tidak ideal bila dipakai untuk menghancurkan limbah plastik yang memiliki ukuran dan bentuk berbeda seperti yang dihasilkan dari sisa-sisa proses cetak injeksi. Maka dari itu, tujuan utama dari penelitian ini adalah melakukan proses perancangan dan pembuatan mesin pencacah plastik (Plastic Waste Shredder) yang dapat digunakan untuk mengolah jenis plastik getas seperti Polyetylene Terephthalate (PET), Polyvinyl Chloride (PVC), High Density Polyethylene (HDPE) dan Low Density Polyethylene (LDPE). Mesin pencacah ini khusus dirancang untuk dapat memproses buangan plastik berukuran besar seperti sisa runner dan cetakan yang cacat dari hasil proses cetak injeksi menjadi serpihan (flake) yang lebih kecil. Pemotong dan komponen pendukung yang dipilih untuk Plastic Waste Shredder harus memiliki kekuatan dan ketangguhan untuk dapat memproses jenis plastik yang disebutkan di atas. Kriteria awal yang ditentukan termasuk kapasitas input mesin berkisar antara 1,9-2,0 liter/menit dan kapasitas ouput minimum 1,8 liter/menit. Adapun dimensi maksimum plastik yang dapat dihancurkan berukuran $100 \mathrm{~mm}$ x $100 \mathrm{~mm}$ x $2 \mathrm{~mm}$ (panjang $\mathrm{x}$ lebar x tebal) dan plastik hasil pencacahan harus memiliki panjang maksimum tidak boleh lebih dari $10 \mathrm{~mm}$.

\section{Material dan metodologi perancangan}

\subsection{Tahapan perancangan}

Tahapan perancangan mesin Plastic Waste Shredder mengikuti metode Pahl dan Beitz [10]. Daftar tuntutan (Demand) dan keinginan (Wish) untuk mesin pencacah plastik dapat dilihat pada Tabel 1. Proses untuk menentukan varian konsep yang dapat dipilih dilakukan dengan menggunakan morphology matrix. Seperti yang ditunjukan pada Tabel 2, ada dua kemungkinan varian desain konsep yang dihasilkan dmorfologi matriks berdasarkan komponen rangka, sistem pemotong, sistem transmisi dan kelistrikan. Ilustrasi Varian 1 dan 2 serta kelebihan dan kekurangan untuk setiap konsep desain terangkum pada Tabel 3.

Tabel 1. Daftar spesifikasi Plastic Waste Shredder

\begin{tabular}{llc}
\hline Tuntutan/Keinginan & Spesifikasi & Skala Prioritas \\
\hline 1. Tuntutan Primer & & \\
- Dapat mencacah plastik dengan hasil pencacahan kurang dari 10 & - Shredding efficiency & Sangat penting \\
mm & - Safety & Sangat penting \\
- Sistem berfungsi dengan baik & & Sangat penting \\
- Dapat dioperasikan oleh tenaga tidak ahli & & \\
\hline 2. Tuntutan Sekunder & - Maksimal 150 RPM & Sangat penting \\
- Kecepatan RPM mesin dapat di atur & - Menggunakan baut & Sangat penting \\
- Mudah dibongkar pasang & \multicolumn{2}{|}{} \\
\hline 3. Keinginan & - Menggunakan belt & Penting \\
- Tidak berisik & - Hitam & Tidak penting \\
\hline
\end{tabular}


Arka Dwinanda Soewono dkk /Jurnal Rekayasa Mesin

p-ISSN: 1411-6863, e-ISSN: 2540-7678

Vol.16|No.1|1-8|April|2021

Tabel 2.Varian konsep desain Plastic Waste Shredder

\begin{tabular}{|c|c|c|}
\hline Sub Komponen & Varian 1 & Varian 2 \\
\hline \multicolumn{3}{|l|}{ Rangka } \\
\hline \multicolumn{3}{|l|}{ Hole Knife } \\
\hline \multicolumn{3}{|l|}{ Shredder knife } \\
\hline \multicolumn{3}{|l|}{ Bearing } \\
\hline \multicolumn{3}{|l|}{ Transmisi } \\
\hline \multicolumn{3}{|l|}{ Perangkat Kontrol } \\
\hline \multicolumn{3}{|l|}{ Motor Penggerak } \\
\hline & Motor $\mathrm{AC}$ & Motor AC \\
\hline
\end{tabular}

Tabel 3. Kelebihan dan kekurangan varian 1 dan 2

\begin{tabular}{|c|c|c|}
\hline & Varian 1 & Varian 2 \\
\hline $\begin{array}{l}\text { Isometric } \\
\text { View }\end{array}$ & & \\
\hline Kelebihan & $\begin{array}{l}\text { - Proses bongkar pasang lebih mudah karena posisi } \\
\text { baut pengencang di posisi yang terjangkau. } \\
\text { - Mata pisau mengekspos sisi tajam sehingga lebih } \\
\text { efektif untuk menghancurkan plastik. } \\
\text { - Ukuran hooper yang lebih kecil }\end{array}$ & 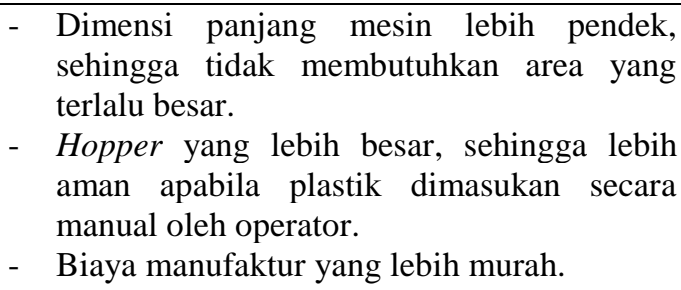 \\
\hline Kekurangan & $\begin{array}{l}\text { - } \begin{array}{l}\text { Dimensi mesin yang lebih panjang } \\
\text { membutuhkan area yang lebih panjang. }\end{array}\end{array}$ & $\begin{array}{l}\text { - Proses bongkar pasang lebih sulit karena } \\
\text { posisi baut yang sulit dijangkau. } \\
\text { - Mata pisau membentuk sudut siku akan } \\
\text { sedikit sulit mencacah plastik }\end{array}$ \\
\hline
\end{tabular}

Tahap terakhir dari proses perancangan yaitu melakukan penilaian kualitatif untuk dua varian konsep tersebut berdasarkan kriteria yang telah ditentukan dari daftar tuntutan/keinginan untuk menentukan konsep desain terbaik. Berdasarkan hasil penilaian di Tabel 4, Varian 1 menjadi pilihan untuk dikembangkan sebagai desain akhir dari Plastic Waste Shredder yang akan dibangun. 
Arka Dwinanda Soewono dkk /Jurnal Rekayasa Mesin

p-ISSN: 1411-6863, e-ISSN: 2540-7678

Vol.16|No.1|1-8|April|2021

Tabel 4. Matrik penilaian varian desain Plastic Waste Shredder

\begin{tabular}{lccc}
\hline & Kriteria & Varian 1 & Varian 2 \\
\hline \multirow{3}{*}{ Nilai Mekanis } & Kemampuan Menghancurkan Plastik & 4 & 3 \\
& Assembly/Disassembly & 4 & 2 \\
& Proses Manufacturing (Permesinan) & 2 & 3 \\
\hline \multirow{3}{*}{ Nilai Ekonomis } & Desain & 4 & 4 \\
& Biaya Produksi \& Material & 3 & 4 \\
\hline & Kemudahan Pemakaian & 3 & 2 \\
\hline
\end{tabular}

\subsection{Metode perhitungan kekuatan material dan pemilihan komponen}

Pada saat proses konstruksi mesin Plastic Waste Shredder, perhitungan kekuatan struktur untuk bagian pemotong, poros penggerak dan transmisi serta rangka penopang dilakukan untuk memastikan agar material yang dipilih untuk bagian tersebut sudah sesuai dengan standar. Tahapan perhitungan dilaksanakan mulai dari ukuran berat komponen Shredder dan Spacer menggunakan software Solidworks, diteruskan dengan perhitungan ukuran motor listrik dan MCB sistem pengaman yang diperlukan dan penentuan ukuran sabuk $V$-belt. Berdasarkan informasi daya motor listrik $(P)$, kecepatan putaran poros $(n)$, dan faktor keamanan $\left(F_{s}\right)$ yang diinginkan; diameter poros yang diperlukan dapat dihitung dengan menggunakan rumus berikut [11]:

$$
D_{\text {poros }}=\sqrt[3]{\frac{9545 \times P \times F_{s}}{n \times \tau_{t}}}
$$

Selanjutnya, tegangan bengkok $\left(\tau_{\mathrm{B}}\right)$ maksimum yang dialami oleh poros dapat dihitung sebagai berikut [12]:

$$
\tau_{B}=\frac{R_{A} \times l \times 32}{2 \pi \times D_{\text {poros }}{ }^{3}}
$$

dimana RA adalah gaya rekasi tumpuan poros dan 1 adalah panjang poros. Di saat bersamaan, poros penggerak ini juga mengalami beban berupa tegangan puntir dari pisau pemotong pada saat proses pencacahan.yang besarnya tegangan puntir $\left(\tau_{\mathrm{P}}\right)$ dapat dihitung sebagai berikut [12]:

$$
\tau_{P}=\frac{M_{P} \times 32}{\pi \times D_{\text {poros }}{ }^{3}}
$$

dimana $\mathrm{M}_{\mathrm{P}}$ adalah momen puntir yang dialami pisau pemotong. Perhitungan kekuatan rangka juga dilakukan untuk memastikan faktor keselamatan. Berdasarkan dari total gaya $\mathrm{F}$ yang harus ditahan dan panjang rangka $\mathrm{L}$, besarnya tegangan $(\sigma)$ dapat dihitung dengan [13]:

$$
\sigma=\frac{F \times L \times 6 H}{B H^{3}-b h^{3}}
$$

Untuk menentukan umur penggunaan bantalan berdasarkan tipe bantalan (q) yang dipakai, beban dinamik yang ditopang (P); kecepatan putaran dari poros (n); dan batas beban yang dapat ditahan oleh bantalan (C) dapat menggunakan persamaan:

$$
L_{h}=\frac{\left(\frac{C}{P}\right)^{q} \times 10^{6}}{n \times 60}
$$




\section{Hasil dan pembahasan}

\subsection{Hasil perhitungan kekuatan dan pemilihan komponen}

Hasil perhitungan kekuatan dan pemilihan komponen untuk mesin pencacah plastik sebagai berikut:

1. Perhitungan massa Shredder dan Spacer

Bagian pemotong yang terdiri dari Shredder dan Spacer dibuat dengan materi besi VCL yang memiliki standar massa jenis sebesar 0,00785 kg/cm ${ }^{3}$ [13]. Ukuran volume Shredder dan Spacer sebesar 42,46 $\mathrm{cm}^{3}$ dan 17,97 $\mathrm{cm}^{3}$ yang didapatkan dari software Solidworks. Dari informasi tersebut, massa Shredder dan Spacer dapat dihitung dimana massa satu buah Shredder adalah 0,333 kg dan massa satu buah Spacer 0,141 kg.

2. Perhitungan motor listrik

Daya motor listrik yang dibutuhkan dapat dihitung berdasarkan massa dan konfigurasi Shredder dan Spacer serta diameter alat pemotong $60 \mathrm{~mm}(0,06 \mathrm{~m})$. Tiap pemotong terdiri dari 6 Shredder dan 5 Spacer dalam konfigurasi $\mathrm{V}$, sehingga dapat menghasilkan output rate paling optimum [14]. Dari informasi tersebut, momen torsi dan daya motor yang dibutuhkan diketahui sebesar 1, $58 \mathrm{Nm}$ dan 0, $463 \mathrm{~kW}$. Dengan menggunakan faktor keamanan dalam perhitungan sebesar 1,5 [15], daya motor listrik yang diperlukan sebesar 0, $6945 \mathrm{~kW}$ atau hampir sebesar 1 HP. Motor listrik yang dipilih memiliki daya sebesar $0,75 \mathrm{~kW}$ dengan tujuan untuk mengurangi peluang plastik tersangkut dan menyebabkan mesin berhenti. Dari perhitungan daya motor listrik, sistem pengaman yang digunakan adalah MCB bertipe C2 [16].

3. Perhitungan ukuran sabuk $V$-belt

Desain dari $V$-belt dihitung untuk motor listrik dengan daya sebesar $0,75 \mathrm{~kW}$, kecepatan putar pulley sebesar 150 rpm, diameter pulley besar sebesar $63 \mathrm{~mm}$ dan diameter pulley kecil sebesar $51 \mathrm{~mm}$. Berdasarkan rumus perhitungan rumus perhitungan dari buku manual [17], panjang sabuk untuk sistem V-belt minimum sebesar 666 $\mathrm{mm}$. Oleh karena itu, sabuk yang dipilih adalah tipe A 32 dari Mitsuboshi dengan panjang $813 \mathrm{~mm}$.

4. Perhitungan diameter poros (main shaft)

Poros transmisi yang digunakan terbuat dari St41 yang merupakan baja konstruksi yang banyak dipakai di pasaran. Material St 41 memiliki permissible shear stress $\left(\tau_{\mathrm{t}}\right.$ ) sebesar $41 \mathrm{~N} / \mathrm{mm}^{2}$. Berdasarkan informasi daya motor listrik $(P)$ sebesar $0,75 \mathrm{~kW}$, kecepatan putaran poros $(n)$ sebesar $150 \mathrm{rpm}$, dan faktor keamanan $\left(F_{s}\right)$ sebesar 5; diameter poros yang diperlukan dapat dihitung dengan menggunakan rumus [1] diketahui sebesar 17,95 mm. Ukuran diameter poros St41 yang dipakai di mesin pencacah adalah $20 \mathrm{~mm}$.

5. Perhitungan tegangan bengkok dan tegangan puntir poros

Total besar gaya yang bekerja pada poros ini adalah 26,8 $\mathrm{N}$ (berasal dari pemotong dan spacer), diameter poros $\left(D_{\text {poros }}\right)$ adalah $20 \mathrm{~mm}$ dan panjang poros $115 \mathrm{~mm}$. Diagram momen untuk poros dapat dilihat di Gambar 1. Gaya reaksi tumpuan $\left(R_{A}\right.$ atau $R_{B}$ ) sebesar setengah dari total gaya yaitu sebesar 13,4 N. Tegangan bengkok yang dialami oleh poros dihitung sebesar $0,96 \mathrm{~N} / \mathrm{mm}$ berdasarkan persamaan (2). Poros juga diberi beban berupa tegangan puntir dari pisau pemotong pada saat proses pencacahan. Mengingat besar gaya di ujung pisau pemotong adalah sebesar 26,8 $\mathrm{N}$ dan panjang pisau dari ujung ke ujung adalah $120 \mathrm{~mm}$, momen puntir $\left(\mathrm{M}_{\mathrm{P}}\right)$ yang dialami pisau pemotong adalah sebesar $1.608 \mathrm{Nmm}$. Tegangan puntir yang dialami poros adalah 2,01 N/mm berdasarkan persamaan (3). Selain itu, poros juga diberi beban dinamis selama proses pencacahan, sehingga perhitungan tegangan tarik sementara perlu dilakukan. Berdasarkan perhitungan teori dengan faktor keselamatan sebesar $5[12,13]$, poros harus dapat menahan tegangan tarik sebesar 8,2 N/mm. Mengingat bahwa permissible 
shear stress $\left(\tau_{\mathrm{t}}\right)$ material St41 masih jauh lebih tinggi dari hasil perhitungan tegangan bengkok, tegangan puntir dan tegangan tarik; dapat dipastikan bahwa poros yang terbuat dari baja St41 dapat memenuhi kriteria keamanan.

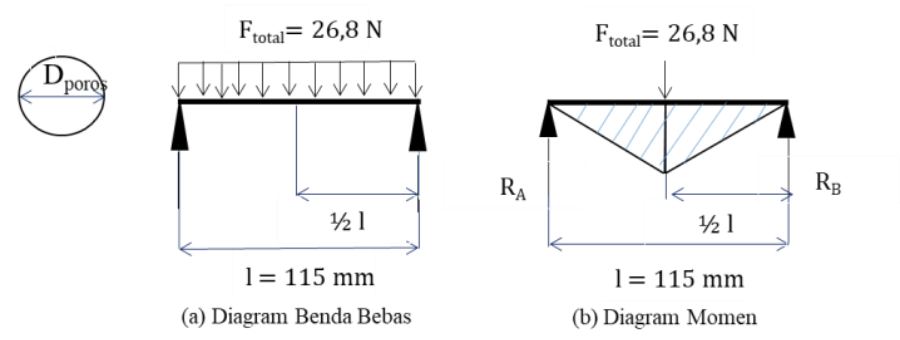

Gambar 1. Diagram gaya dan momen di poros

6. Perhitungan kekuatan rangka dan umur bantalan

Rangka penopang alat pemotong dan poros utama terbuat dari besi siku yang dibentuk agar memiliki penampang hollow seperti di Gambar 2. Material dari besi siku tersebut adalah mild steel (MS) dengan tegangan luluh sebesar $370-450 \mathrm{~N} / \mathrm{mm}^{2}$. Rangka memiliki dimensi luar $(\mathrm{H}=\mathrm{M})$ sebesar $35 \mathrm{~mm}$ dan dimensi dalam $(\mathrm{h}=\mathrm{m})$ sebesar 31,6 mm. Berdasarkan total gaya $(\mathrm{F})$ yang harus ditahan oleh rangka sebesar 588,6 N dan panjang rangka (L) adalah $1000 \mathrm{~mm}$. Besarnya tegangan yang diberikan pada rangka adalah 245,5 $\mathrm{N} / \mathrm{mm}^{2}$ berdasarkan persamaan (4). Karena besarnya tegangan ini masih lebih kecil dari titik luluh middle steel, desain rangka masih sesuai dengan kriteria keselamatan. Dari perhitungan, besarnya beban dinamik dari alat pemotong diketahui sebesar 2,412 kN. Tipe bearing yang dipakai untuk mesin Plastic Waste Shredder adalah UCFL 202 dengan batas beban sebesar 12,8 kN dan nilai faktor $\mathrm{q}=3$. Dari persamaan (5), perkiraan umur pakai dari bearing ini adalah 16605 jam.

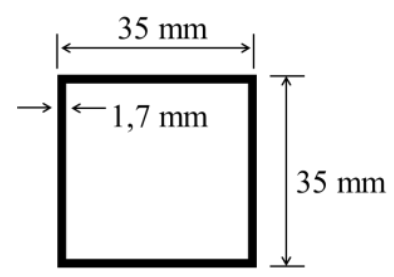

Gambar 2. Penampang rangka

\subsection{Perwujudan mesin pencacah plastik}

Proses rancang bangun mesin Plastic Waste Shredder telah berhasil dilaksanakan. Mesin pencacah plastik ini dirancang secara spesifik untuk dapat menghancurkan sisa runner dan cetakan yang cacat hasil dari proses cetak injeksi plastik. Mesin Plastic Waste Shredder yang telah dibangun dapat dilihat di Gambar 3. Mesin pencacah plastik ini telah melewati tahapan uji coba elektrik maupun mekanik. Pada uji coba elektrik tanpa menggunakan input limbah plastik, rangkaian kontrol elektrik serta sistem pengaman dapat berjalan secara baik dan benar. Motor listrik dapat memutar pemotong tanpa ada kendala serta kecepatan putaran motor dapat dikendalikan sesuai dengan keinginan operator. Mesin pencacah plastik kemudian melewati simulasi mekanik dimana proses uji coba pencacahan dilakukan dengan menggunakan sampel runner yang sudah disiapkan. Mesin dijalankan pada kecepatan putaran 150 rpm sesuai dengan hasil perhitungan. Gambar 4 menunjukan plastik runner yang belum tercacah dan sesudah melalui mesin pencacah. Dapat dilihat bahwa plastik yang yang sudah tercacah memiliki dimensi panjang antara $2 \mathrm{~mm}$ sampai $5 \mathrm{~mm}$ sesuai dengan daftar tuntutan untuk mesin Plastic Waste Shredder yang terangkum di Tabel 1. 
Arka Dwinanda Soewono dkk /Jurnal Rekayasa Mesin

p-ISSN: 1411-6863, e-ISSN: 2540-7678

Vol.16|No.1|1-8|April|2021

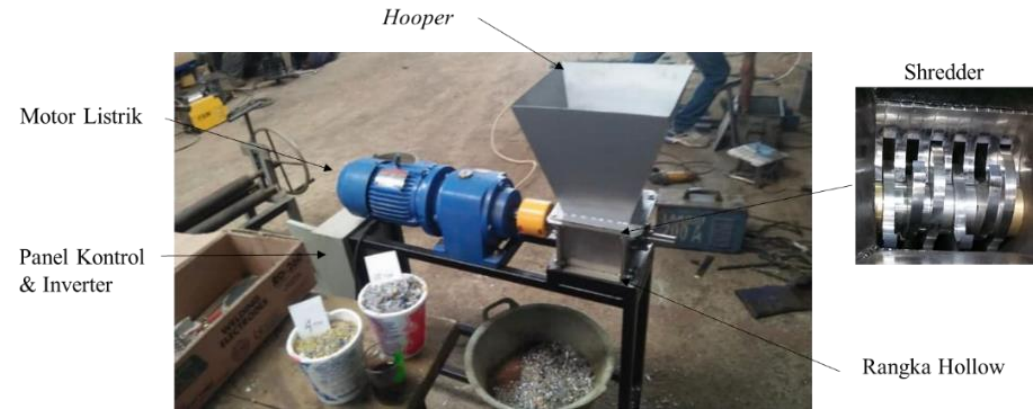

Gambar 3. Plastic Waste Shredder

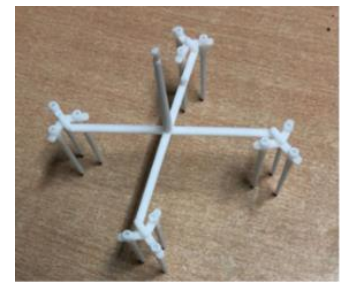

(a)

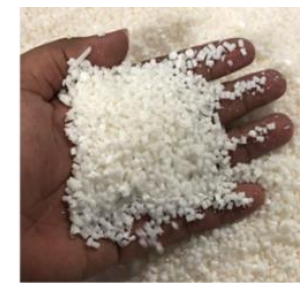

(b)

Gambar 4. Runner yang belum (a) dan sudah (b) tercacah

Untuk mengevaluasi kinerja dari mesin Plastic Waste Shredder, lima test run dilakukan pada waktu yang berbeda dengan jumlah input limbah plastik dan durasi waktu pencacahan yang bervariasi. Jumlah plastik yang tercacah kemudian diukur selama percobaan berlangsung. Ringkasan hasil percobaan dirangkum pada Tabel 5. Dapat dilihat bahwa performa mesin pencacah telah memenuhi tuntutan design specification di Tabel 1 dengan kapasitas input rata-rata sebesar 1,94 liter/menit dan kapasitas ouput mencapai 1,84 liter/menit.

Tabel 5. Hasil uji mesin Plastic Waste Shredder

\begin{tabular}{lcccccc}
\hline \multicolumn{1}{c}{ Test Run } & $\mathbf{1}$ & $\mathbf{2}$ & $\mathbf{3}$ & $\mathbf{4}$ & $\mathbf{5}$ & Rata - Rata \\
\hline Input limbah plastik (liter) & 58,7 & 89,3 & 58,2 & 27,65 & 119,55 & 70,68 \\
Output plastik yang tercacah (liter) & 56,5 & 83,3 & 54,3 & 25,9 & 115,8 & 67,16 \\
Durasi proses pencacahan (menit) & 30,0 & 45,0 & 30,0 & 15,0 & 60,0 & 36,00 \\
Kapasitas Input (liter/menit) & 1,96 & 1,98 & 1,94 & 1,84 & 1,99 & 1,94 \\
Kapasitas Output (liter/menit) & 1,88 & 1,85 & 1,81 & 1,73 & 1,93 & 1,84 \\
\hline \multicolumn{1}{c}{ Shredding Efficiency } & $\mathbf{0 , 9 6}$ & $\mathbf{0 , 9 3}$ & $\mathbf{0 , 9 3}$ & $\mathbf{0 , 9 4}$ & $\mathbf{0 , 9 7}$ & $\mathbf{0 , 9 5}$ \\
\hline
\end{tabular}

Dari data hasil pengukuran, shredding efficiency dari mesin Plastic Waste Shredder dapat dihitung berdasarkan rasio kapasitas output per input. Dapat dilihat bahwa mesin pencacah yang telah dirancang dapat menghasilkan shredding efficiency berkisar antara 93 - 97\%. Nilai efisiensi ini sudah hamper mirip dengan shredding efficiency yang dihasikan oleh mesin pencacah yang dikembangkan oleh David dkk [18]. Berdasarkan pengamatan selama uji coba, mesin pencacah juga tidak pernah mengalami kegagalan yang disebabkan oleh terjepitnya plastik diantara mata pisau meskipun jumlah plastik yang diproses cukup banyak. Oleh sebab itu, kinerja mesin Plastic Waste Shredder dapat dinyatakan memuaskan dan telah sesuai dengan kriteria design yang diinginkan.

\section{Kesimpulan}

Mesin Plastic Waste Shredder telah berhasil dirancang dan dibangun untuk dapat mencacah limbah plastik dalam bentuk runner dan material sisa proses cetak injeksi. Sebagai bagian dari proses rancang bangun, perhitungan kekuatan 
Arka Dwinanda Soewono dkk /Jurnal Rekayasa Mesin p-ISSN: 1411-6863, e-ISSN: 2540-7678 Vol.16|No.1|1-8|April|2021

mekanika struktur untuk bagian alat pemotong, poros utama, sistem transmisi $V$-belt dan rangka penopang telah dilakukan agar konstuksi mesin sesuai dengan kriteria keselamatan. Berdasarkan hasil uji coba, mesin pencacah plastik ini berfungsi sesuai dengan tuntutan design specification dimana output plastik yang tercacah berukuran kurang dari $10 \mathrm{~mm}$. Hasil pengukuran selama percobaan juga menunjukan bahwa mesin pencacah memiliki kapasitas input rata-rata 1,94 liter/menit dan kapasitas ouput 1,84 liter/menit dengan kemampuan shredding efficiency sebesar 95\%. Berdasarkan informasi di atas, kinerja mesin Plastic Waste Shredder dapat dinyatakan memuaskan.

\section{Daftar Pustaka}

[1] Rosato, D.V., Rosato, M.G., Injection molding handbook. $3^{\text {rd }}$ edition, United States: Kluwer Academic Publishers; 2000. p 24.

[2] Kaswadi, A., Tauhid, M.A., Optimalisasi perancangan runner dan gate cetakan injeksi plastik. Prosiding SNTTM XVI; 5 - 6 Oktober 2017; Surabaya, Indonesia. p. 15.

[3] Takarada, R.K. An experimental investigation of runner based flow imbalances during injection molding processes in multicavity molds. United States: Lehigh University; 2016. p 928.

[4] Lam, Y.C., Seow, L.W., Cavity balance for plastic injection molding. Polymer Engineering \& Science. 2000; 40 (6), p. 1273.

[5] CNN Indonesia. Indonesia penyumbang sampah plastik terbesar kedua di dunia. http://www.cnnindonesia.com/gaya-hidup/20160222182308-277-112685/indonesia-penyumbang-sampah-plastikterbesar-ke-dua-dunia/ 23 Febuari 2016. CNN: Headline; 2016 (Diakses pada tanggal 28 Mei 2020).

[6] Bocz, K., Toldy, A., Development of flame retarded self-reinforced composites fromautomotive shredder plastic waste. Polymer Degradation and Stability. 2012; 97 (3), p. 221.

[7] Orhorhoro, E.K., Ikpe, A.E., Tamuno, R.I., Performance analysis of locally design plastic crushing machine for domestic and industrial use in Nigeria. European Journal of Engineering Research and Science. 2018; 1(2), p. 26.

[8] Aryani, N., Buchori, D., Setiawan, A.B., Design of a plastic shredder machine. Proceeding of International Conference on Engineering, Advance Science and Industrial Application; 6-7 September 2018; Surabaya, Indonesia. IPTEK Journal of Proceedings Series; 2019, 3, p 35.

[9] Sudhakara, R., Thunga, R., Design and development of mini plastic shredder machine. IOP Conference Series: Materials Science and Engineering. 2018; 455, p 012119.

[10] Pahl, G., Beitz, W., Engineering design: a systematic approach. United States: Springer; 2014.

[11] Sudibyo, B., Poros penyangga dan poros transmisi. Indonesia : ATMI Press; 2011.

[12] Sudibyo, B., Menghitung bantalan gelinding yang berputar. Indonesia : ATMI Press; 2011.

[13] Rijanto, T., Mekanika teknik bahan. Indonesia : ATMI Press; 2011.

[14] Asroni, M., Djiwo, S., Setyawan, E.Y., Pengaruh model pisau pada mesin sampah botol plastik. Jurnal Aplikasi dan Inovasi Ipteks SOLIDITAS. 2018; 1 (1), p. 29.

[15] Ekman, R., Development of a plastic shredder. Sweden: Lund University; 2018. p 12.

[16] Heryana, N., Power electronic fundamental. Indonesia : Institut Teknologi Bandung; 2011.

[17] Sudibyo, B., Perhitungan transmisi sabuk. Indonesia : ATMI Press; 2011.

[18] David, A., Joel, O.O., Design and construction of a plastic shredder machine for recycling and management of plastic wastes. International Journal of Scientific \& Engineering Research. 2018; 9 (5), p. 1379. 